\title{
Correlation between Body Mass Index and Disability in Patient with Chronic Low Back Pain
}

\author{
Tiang Soon Teck, ${ }^{1}$ Tertianto Prabowo, ${ }^{2}$ Nani Kurniani ${ }^{3}$ \\ ${ }^{1}$ Faculty of Medicine Universitas Padjadjaran, ${ }^{2}$ Department of Physical Medicine and \\ Rehabilitation Faculty of Medicine Universitas Padjadjaran/Dr. Hasan Sadikin General Hospital \\ Bandung, ${ }^{3}$ Department of Neurology Faculty of Medicine Universitas Padjadjaran/Dr. Hasan \\ Sadikin General Hospital Bandung
}

\begin{abstract}
Background: Low back pain is discomfort presented below the margin of the 12th thoracic rib and above the inferior gluteal fold with or without leg pain. It is also a major cause of disability. Several risk factors have been identified for contributing low back pain. It is important to determine whether body mass index (BMI) can affect the disability in patients with chronic low back pain. Oswestry disability index (ODI) questionnaire has been used to measure the severity of disability. Thus, the focus of study was to determine correlation between BMI and disability in patients with chronic low back pain.
\end{abstract}

Methods: Sixty two patients aged 18 years old or more who were clinically diagnosed as having low back pain at least 3 months participated in this study in the period of October to November 2015 in the Department of Physical Medicine and Rehabilitation of Dr. Hasan Sadikin General Hospital Bandung. Total sampling method was used. Gender, age, weight, height, BMI and disability were recorded using ODI questionnaire. This analytical study was cross sectional study and the ordinal variable was analyzed using linear regression analysis.

Results: Females had higher proportion (77). Chronic low back pain patients were equally distributed on normal weight and overweight categories. Patient with chronic low back pain had higher chances of developing moderate disability. There were positive correlation between BMI and disability. Nevertheless, there was no statistically analysis difference between model 1 and 2 .

Conclusions: The BMI affects the disability in patients with chronic low back pain. [AMJ.2016;3 (4):624-8]

Keywords: Body mass index, disability, low back pain, Oswestry disability index questionnaire

\section{Introduction}

Disability is defined as any restriction or lack of ability to perform an activity in the manner or within the range considered normal for a human being according to the World Health Organization (WHO). There are over one billion people $(15 \%)$ with disabilities in the world. Between hundred and ten million and hundred and ninety million people aged fifty years old and older have obvious problem in functioning. ${ }^{1}$ Body mass index (BMI) is a reliable indicator of body fat for most people but BMI is not a diagnostic tool. Furthermore, BMI is cheap and easy to use for doctors and even general population. The BMI is categorized into few groups which are underweight, normal, overweight, and obese. ${ }^{2}$
Low back pain is one of the very common health problem worldwide and it is also a major cause of disability which affecting performance at work and general wellbeing. Low back pain can be categorized into three types, i.e. acute, sub-acute, and chronic. Back pain is not a disease but more like a symptom thus it is considered neither a disease nor a diagnostic entity of any sort. ${ }^{3,4}$ The 2010 Global Burden of Disease Study has showed that low back pain is among the top 10 diseases and injuries with the highest number of disabilityadjusted life year (DALYs) worldwide, and ranked sixth in term of the overall disease burden. In industrialized countries, the lifetime prevalence of non-specific (common) low back pain is estimated $60 \%$ to $70 \%$ in adult. While one-year prevalence is $15 \%$ to $45 \%$ and adult

Correspondence: Tiang Soon Teck, Faculty of Medicine, Universitas Padjadjaran, Jalan Raya Bandung-Sumedang Km.21, Jatinangor, Sumedang, Indonesia, Phone: +6287726068500 Email: thompson_0511@hotmail.com 
incidence is $5 \%$ per year. Cases of low back pain increase in a considerable amount due to deterioration of the intervertebral discs in older people as the world populations aged. ${ }^{3,5,6}$

Besides, obesity is one of the lifestyle factors that causes low back pain and the excessive body weight has mechanical ill effects on the back caused by excessive weight bearing causing disability. ${ }^{7}$ Excessive height also increases pressure on the spine thus limiting the range of motion of back which results in disability. Thus, the focus of this study was to identify the correlation between BMI and disability based on Oswestry Disability Index (ODI) in patient with chronic low back pain at Physical Medicine and Rehabilitation Department, Dr. Hasan Sadikin General Hospital, Bandung.

\section{Methods}

Cross sectional study was carried out in the period of October to November 2015. This study was performed with approval from Health Research Ethics Committee, Faculty of Medicine, Universitas Padjadjaran. The instruments used were ODI questionnaire Indonesian version, measuring tape, and electronic weighing scale.

Total sampling method was used in which patients that administered to Department of Physical Medicine and Rehabilitation, Dr. Hasan Sadikin General Hospital, Bandung were selected and filtered through several inclusion and exclusion criteria. Patients aged 18 years old or more who were clinically diagnosed by doctor as having low back pain at least 3 months were included in the study; Furthermore, patients with neck cancer or trauma which cause radiating back pain were excluded to prevent alteration of the data collected.

Eligible subjects were approached. Those willing to participate then received explanation about the procedure and purpose of the test were explained, and then asked to fill up consent form. After consent was obtained, height and weight of the subjects were measured using standard scales and recorded, further interpreted into BMI based on WHO guidelines. Then, based on calculated BMI, subjects were categorized into four groups: below $18.5 ; 18.5$ to $24.9 ; 25$ to 29.9 ; and 30 and above indicating obese, indicating underweight, normal weight, overweight, and obese, consecutively.

The disability specifically from low back pain was measured using Indonesian version of ODI questionnaire. The ODI has ten items including: pain intensity, personal care, lifting, walking, sitting, standing, sleeping, sex, social, and travel. There are six statements in each item with scores of 0 through 5 and the patient chose the statement that was appropriate to his or her ability or current condition. The statement correlating to score of 5 represented the greatest disability and the statement correlating with a score of 0 indicated the least disability. The questionnaire was filled by subjects, but they could ask for explanation during the process. The ODI was interpreted into 5 group: $0 \%$ to $20 \%$ (minimal disability), $21 \%$ to $40 \%$ (moderate disability), $41 \%$ to $60 \%$ (severe disability), $61 \%$ to $80 \%$ (crippled), and $81 \%$ to $100 \%$ (bed bound ). ${ }^{8,9}$

Data obtained were ordinal and continuous variables, therefore, the correlation between BMI and ODI was analyzed using linear regression method. The result was statistically significant when the p-value was $<0.05$.

\section{Results}

During study period, there were 62 subjects recruited. Females had higher proportion (77 vs. 23). Patients with older age than the mean age had increased chances to develop low back pain (Table 1).

Chronic low back pain patients were equally

Table 1 General Characteristics of Patient

\begin{tabular}{lcc}
\hline \multicolumn{1}{c}{ Characteristics } & N(\%) & Mean(SD) \\
\hline Gender & & \\
Male & $14(23)$ & \\
Female & $48(77)$ & \\
Age(years) & & $54.21(14.52)$ \\
Weight $($ Kg) & & $60.92(7.67)$ \\
Height $(\mathrm{cm})$ & & $155.92(7.48)$ \\
\hline
\end{tabular}


Table 2 Distribution of Chronic Low Back Pain Patient According Body Mass Index

\begin{tabular}{lcc}
\hline \multicolumn{1}{c}{ BMI* Category $^{*}$} & $\mathbf{N}=\mathbf{6 2}$ & \% \\
\hline Normal & 29 & 47 \\
Overweight & 29 & 47 \\
Obese & 4 & 6 \\
\hline
\end{tabular}

*BMI= Body mass index

Table 3 Distribution of Chronic Low Back Pain Patient According Disability

\begin{tabular}{lcc}
\hline \multicolumn{1}{c}{ Disability Category } & $\mathbf{N = 6 2}$ & $\mathbf{\%}$ \\
\hline Minimal Disability & 10 & 16 \\
Moderate Disability & 36 & 58 \\
Severe Disability & 15 & 24 \\
Cripple & 1 & 2 \\
\hline
\end{tabular}

distributed on normal weight and overweight categories, but when added obese category, it had showed that abnormal weight patients had higher odds to get low back pain (Table 2).

Patient with chronic low back pain had higher chances of developing moderate disability. This result occurred because it had the highest proportion of people (Table 3). No subjects were bed bound.

Linear regression was used to analyzed BMI and disability. The total variability was explained by linear regression with BMI as predictor (Figure 1).

After sex and age were adjusted, there were positive correlation between BMI and disability as indicated in model 2. Nevertheless, there was no statistically analysis difference between model 1 and 2 because both of them were significant and showed positive correlation (Table 4).

\section{Discussion}

In this study, the subjects were patients who were clinically diagnosed as low back pain for more than 3 months and must be from aged 18 to elderly. It was in accordance with the other study which stated that the incidence of low back pain increases on people aged toward their $50-60$ s. $^{10}$

The result showed that females had higher proportion, it was indicating that women had higher chances to develop low back pain.

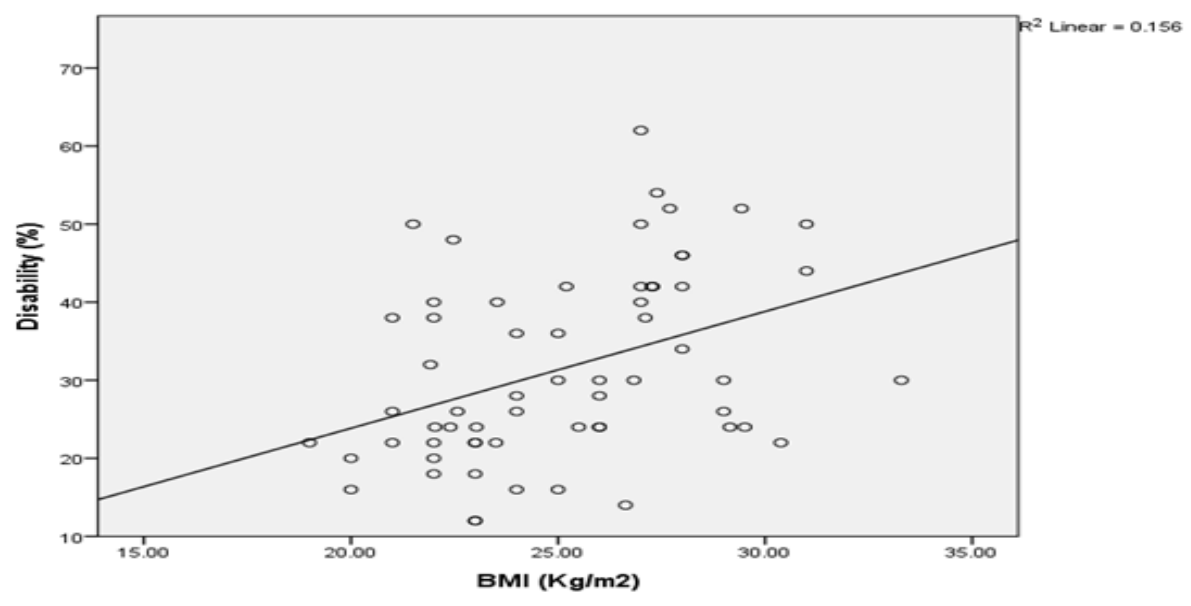

Figure 1 Distribution of Disability According to BMI 
Table 4 Effect of Body Mass Index to Disability

\begin{tabular}{lcc}
\hline & Model 1* & Model 2** \\
\hline BMI* coefficient(SD) & $0.472(0.130)$ & $0.433(0.143)$ \\
Sex & & 0.097 \\
Age & & 0.002 \\
p-value & 0.001 & 0.004 \\
\hline
\end{tabular}

Note: * Before adjusted for sex and age, ${ }^{* *}$ After adjusted for sex and age, ${ }^{* * *}$ BMI= Body mass index, \# Analyzed using linear regression method

People with higher value than mean weight and mean height had greater possibilities to develop disability.

There was positive correlation between the BMI and disability in patients with chronic low back pain. Several factors might contribute to the occurrence of this significant result.

The correlation between body weight and both morbidity and mortality has been examined extensively but relatively few researches have investigated on the correlation between body weight and disability in low back pain. Although few studies have been conducted, obesity has shown higher prevalence of disability in cross-sectional and longitudinal study. Additionally, the correlation between BMI and disability is the strongest among those who are underweight and obese. Besides, obesity may lead to disability as a consequence of increased body weight, associated co-morbidities, environmental factors, or a combination of these. Obesity causes greater mechanical stress on joints and the spine of patients, the risk of back pain and osteoarthritis that may in turn limit mobility of the body. Furthermore, obesity also leads to increase protein glycation in connective tissue or atherogenesis which decreases blood flow to the spine. Thus, some obese people face difficulties in performing several movements such as walking, climbing steps, driving, or stressing. This problem in turn leads to physical inactivity, pain and discomfort, functional limitations and mental distress and range of motion decrease. ${ }^{5,11,12}$ However, in this study, BMI causes increased disability in chronic low back pain patients.

Furthermore, there is a study showed that when whole body and upper and lower limbs of an individual have a greater fat mass, it has higher tendency to have higher levels of low back pain intensity and disability. Based on the analysis of data collected, it has proven that there is correlation between fat mass and pain intensity and disability. Thus, this study revealed that there is correlation between BMI and disability. In this study, body composition was not measured, however, the BMI has been used and does not provide specific information on fat and lean tissue mass. ${ }^{13}$

However, there are some limitations in this study. The sample biased because this study used self-reporting questionnaire to measure the quality of pain and disability. Of this study, each individual has different endurance level on pain which can affect the result of the study. Short research period also may affect the result of study because more subjects are usually needed to represent the populations in order to increase the validity of result. The validation of the Indonesian version ODI questionnaire from the expert has not yet been conducted, thus it may affect the answers given by patient further altering the result of study. In conclusion, there is positive linear correlation between BMI and disability in patients with chronic low back pain. Since the result showed positive correlation, this study suggested that chronic low back pain patients need to decrease their weight and maintain it at normal value. Besides, the physicians can plan a routine exercise for the low back pain patients.

\section{References}

1. Klemenc Ketiš Z. Predictors of healthrelated quality of life and disability in patients with chronic nonspecific low back pain. Slovenian Med J. 2011;80(5):379-85.

2. Smeets R, Köke A, Lin CW, Ferreira M, Demoulin C. Measures of function in low back pain/disorders: low back pain rating scale (LBPRS), oswestry disability index (ODI), progressive isoinertial lifting evaluation (PILE), quebec back pain disability scale (QBPDS), and RolandMorris disability questionnaire (RDQ). Arthritis Care Res. 2011;63(S11):S158-73.

3. Duthey B. Background paper 6.24 low back pain. Geneva: WHO; 2013. 
4. Murray CJ, Vos T, Lozano R, Naghavi M, Flaxman AD, Michaud C, et al. Disabilityadjusted life years (DALYs) for 291 diseases and injuries in 21 regions, 19902010: a systematic analysis for the global burden of disease study 2010. Lancet. 2013;380(9859):2197-223.

5. Koyanagi A, Stickley A, Garin N, Miret M, Ayuso-Mateos JL, Leonardi M, et al. The association between obesity and back pain in nine countries: a cross-sectional study. BMC Public Health. 2015;15(1):123-37.

6. Lionel K. Risk factors forchronic low back pain. J Community Med Health Educ. 2014;4(271):2161-0711.

7. Tobin D, Shaw T, Daly E. Obesity and low back pain a review of the literature. Greater Glasgow Back Pain Service (GGBPS). 2009;10(1):1-25.

8. Mehra A, Baker D, Disney S, Pynsent P. Oswestry disability index scoring made easy. Ann R Coll Surg Engl. 2008;90(6):49799.

9. Jeremy C. T. Fairbank. Why are there different versions of the oswestry disability index? a review. J Neurosurg Spine. 2014;20(1):83-6.

10. Kwon MA, Shim WS, Kim MH, Gwak MS, Hahm TS, Kim GS, et al. A correlation between low back pain and associated factors: a study involving 772 patients who had undergone general physical examination. J Korean Med Sci. 2006;21(6):1086-91.

11. Zdziarski LA, Wasser JG, Vincent HK. Chronic pain management in the obese patient: a focused review of key challenges and potential exercise solutions. J Pain Res. 2015;8(1):63-77.

12. Gatineau M, Hancock C, Dent, M. Adult disability and obesity. London: Public Health England; 2013.

13. Urquhart DM, Berry P, Wluka AE, Strauss BJ, Wang Y, Proietto J, et al. 2011 young investigator award winner: increased fat mass is associated with high levels of low back pain intensity and disability. Spine. 2011;36(16):1320-5. 